\title{
Sensory deficit and the risk of pedestrian injury
}

\author{
Ian Roberts, Robyn Norton
}

\begin{abstract}
Objectives-To examine the association between sensory deficit and the risk of child pedestrian-motor vehicle collisions.

Setting-The Auckland region of New Zealand.

Methods-A community based case-control study was conducted. Cases $(n=190)$ were all children ( $<15$ years) killed or hospitalised as a result of a pedestrian injury occurring on a public road between 1 January 1992 and 1 March 1994. Controls $(n=479)$ were a random sample of the child population.
\end{abstract}

Results - The risk of pedestrian injury for children whose parents reported abnormal vision was over four times that of children with reported normal vision (odds ratio $=4.25,95 \%$ confidence interval 1.68 to $10 \cdot 8)$. The risk of injury for children whose parents reported abnormal hearing was close to twice that of children with reported normal hearing (odds ratio= $1 \cdot 73,95 \%$ confidence interval 0.83 to $3 \cdot 61$ ).

Conclusions-Children with sensory deficits constitute a high risk group for pedestrian injuries. Paediatricians caring for children with sensory impairments should be aware of this increased risk.

(Injury Prevention 1995; 1: 12-14)

Keywords: case-control studies, accidents, sensory deficit.

Children with special needs constitute a high risk group for several categories of unintentional injury. For example, children with epilepsy have an increased risk of submersion

Starship Children's Health: South Pacific, Auckland, New Zealand and Injury Prevention Research Centre, University of Auckland I Roberts

Injury Prevention Research Centre, University of Auckland R Norton

Correspondence to: $\mathbf{D r}$ Ian Roberts, Community Paediatric Research, C538, Montreal Children's Hospital, McGill University, 2300 Tupper, Montreal,
Quebec H3H 1P3, Canada. study to assess the contribution of sensory deficits in child pedestrian-motor vehicle collisions. Other analyses of this data have been presented elsewhere. ${ }^{6}$

\section{Methods}

Cases in the study were all children younger than 15 years, resident within the Auckland region of New Zealand, who were killed or admitted to hospital as a result of a pedestrian injury occurring on a public road, between 1 January 1992 and 1 March 1994. Children who were injured after having been reversed over in residential driveways and car parks were excluded from the analyses because we considered it unlikely that a sensory deficit would be etiologically related to this mechanism of injury. Had we done so, their inclusion might have biased the odds ratio towards the null. The Auckland region has a predominantly urban population of 936981 of whom approximately 213177 are under 15 years. ${ }^{7}$ Fatal cases were identified by regular surveillance of the records of the coroner's pathologist. In Auckland, all children whose deaths have resulted from injury are subject to a coronor's postmortem examination. Hospitalised cases were identified through a monitoring system established at both of the hospitals in the region that admit injured children.

Controls were approximately frequency matched on gender and age in the following categories: under age 5,5-9, and 10-14 years. Controls for school aged cases were selected by first randomly selecting a school from a list of all schools (including private and special schools) in the study region, with a sampling probability in proportion to the number of children on the school roll. The selected school was then visited by the study staff who randomly selected a school child from the school roll.

Controls for preschool cases were selected by initially selecting a school child using the method described above. Then, using the street address of the selected school child as the starting point, homes were visited successively in a predetermined direction until a home with a preschool child was found. The parents of this child were then provided with information about the study and invited to participate. If a home was visited when the occupants were out, the neighbours were contacted and asked if a preschool child lived in the selected home. If so, repeated calls were made, at different times of the day, until either the family of the eligible acquired disability. Ascertaining the etiologic role of sensory deficit may have important implications for prevention. In this paper we use data from a community based case-control 
control was contacted or four separate visits were made, in which case a non-response was recorded and the next household was visited.

After each subject was identified, an interview was scheduled with the parents. Parents of cases and controls completed a structured, interviewer administered questionnaire that included questions about a number of sociodemographic characteristics and about the health status of the child. Socioeconomic position was classified according to the New Zealand based Elley Irving scale. ${ }^{8}$ The presence of a hearing or visual problem was determined by the qustions 'Does your child have normal hearing?' and 'Does your child have normal vision?'

Relative risks were estimated by calculation of odds ratios. Univariate odds ratios have $95 \%$ confidence intervals (CI) calculated by the method of Cornfield. ${ }^{9}$ Adjusted odds ratios were obtained by unconditional multiple logistic regression, as were their $95 \% \mathrm{CI}$. The study was approved by the University of Auckland human subjects ethics committee.

\section{Results}

A total of 265 injured child pedestrians were identified by the surveillance system over the study period. The parents of 258 of these

Table 1 Age and gender distribution for cases and controls

\begin{tabular}{lcl}
\hline Variable & $\begin{array}{l}\text { No }(\%) \text { cases } \\
(n=190)\end{array}$ & $\begin{array}{l}\text { No }(\%) \text { controls } \\
(n=479)\end{array}$ \\
\hline $\begin{array}{l}\text { Age (years) } \\
<5\end{array}$ & $37(20)$ & $159(33)$ \\
$5-9$ & $91(48)$ & $205(43)$ \\
$\begin{array}{c}10-14 \\
\text { Gender }\end{array}$ & $62(33)$ & $115(24)$ \\
Male & $115(61)$ & $282(59)$ \\
Female & $75(40)$ & $197(41)$ \\
\hline
\end{tabular}

Table 2 Numbers and univariate odds ratios for sociodemographic variables

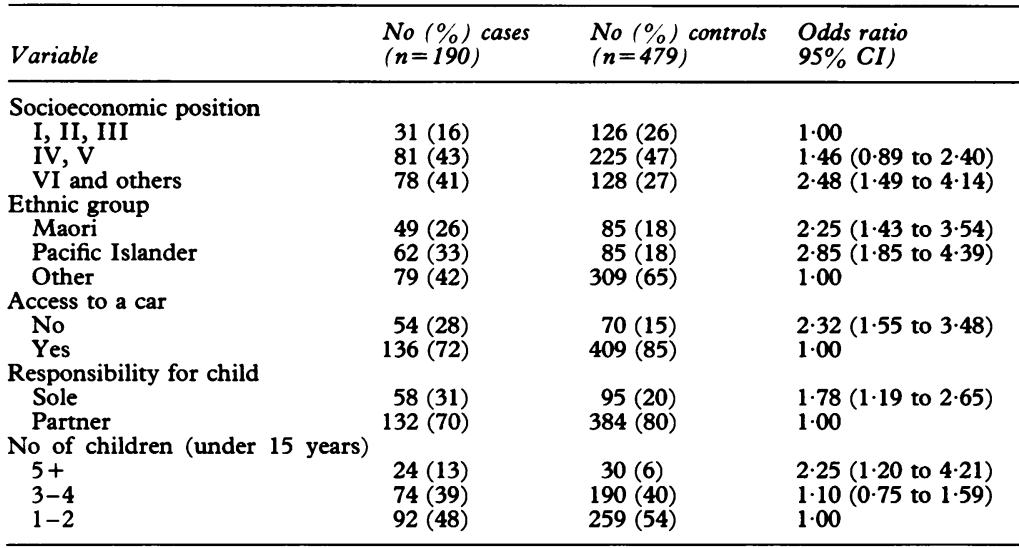

Table 3 Numbers and univariate odds ratios for sensory deficit variables

\begin{tabular}{lccl}
\hline Variable & $\begin{array}{l}\text { No }(\%) \text { cases } \\
(n=190)\end{array}$ & $\begin{array}{l}\text { No }(\%) \text { controls } \\
(n=479)\end{array}$ & $\begin{array}{l}\text { Odds ratio } \\
95 \% C I)\end{array}$ \\
\hline $\begin{array}{l}\text { Hearing problem } \\
\text { Yes }\end{array}$ & $15(8)$ & $19(4)$ & $2.08(0.98$ to 4.39$)$ \\
$\begin{array}{l}\text { No } \\
\text { Visual problem }\end{array}$ & $175(92)$ & $460(96)$ & 1.00 \\
$\quad$ Yes & $13(7)$ & $8(2)$ & $4.32(1.64$ to 11.62$)$ \\
No & $177(93)$ & $471(98)$ & 1.00 \\
\hline
\end{tabular}

children agreed to participate in the study, a response rate of $97 \%$. Of the 258 participating cases, $190(74 \%)$ were injured on public highways, $53(21 \%)$ in residental driveways, 11 $(4 \%)$ in car parks, and four $(2 \%)$ children in public parks.

A total of 485 eligible control children were identified over the study period. The parents of 479 of these children agreed to participate in the study, a response rate of $99 \%$. Subsequent analyses are, therefore, based on the 190 participating cases who were injured on public roads and 479 controls. Table 1 shows the distribution of cases and controls by age and gender.

Univariate odds ratios and $95 \% \mathrm{CI}$ are presented in tables 2 and 3 for sociodemographic variables and for personal health related variables. There was a strong relationship between pedestrian injury risk and socioeconomic position (table 2). Children from families in the lowest socioeconomic stratum had a risk of injury over twice that of children in the highest socioeconomic stratum. The risk of injury for Pacific Island children was close to three times greater than that for children in the reference category, with the risk for Maori children being between two and three times that of children in the reference category. Children from single parent families and children from families with five or more children were also at increased risk. The presence of a visual problem was associated with a fourfold increase in the risk of pedestrian injury (table 3). The risk of injury for children whose parents reported a hearing problem was twice that of children without a hearing problem.

The risks associated with a sensory deficit were then examined after controlling for potential confounding variables in a multiple logistic regression model. Variables incorporated into the model as potential confounders included age, sex, socioeconomic position, and ethnic group. The adjusted odds ratio for a visual problem was 4.25 (95\% CI 1.68 to $10 \cdot 8)$. The adjusted odds ratio for a hearing problem was $1.73(95 \%$ CI 0.83 to 3.61$)$.

Of the 190 pedestrian injuries, 30 occurred when children were struck by vehicles failing to stop at pedestrian crossings. Since it is possible that the presence of a sensory deficit is etiologically unimportant for this mechanism of injury, the risks associated with visual and hearing deficits were also examined excluding these 30 cases. The adjusted odds ratio for a visual problem was $5.32(95 \%$ CI 2.09 to 13.6$)$ and the adjusted odds ratio for a hearing problem was 2.05 (95\% CI 0.98 to $4 \cdot 28)$.

\section{Discussion}

The results of this study indicate that the presence of abnormal vision is associated with a greatly increased risk of pedestrian injury. The risk of injury for children whose parents reported a visual problem was over four times that of children whose parents reported normal vision. The risk of injury for children whose parents reported abnormal hearing was approximately twice that of children with normal 
hearing. These results suggest that children with sensory deficits constitute a subgroup of children at high risk for pedestrian injury to which preventive measures might be preferentially directed.

The control group in this study was a random sample of the child population selected from a sampling frame of all schoolchildren, including those in special schools. Since school registers were used to select controls, children absent from school would still have been selected. Because controls were age frequency matched to the cases before exclusion of the driveway cases, the distribution of ages between cases and controls is not as close as it might have been. Nevertheless, age was adjusted for in the analyses by inclusion in the multivariate logistic regression models. A particular strength of this study was the very high response rates obtained from both cases and controls. As a result, even if the prevalence of sensory deficit among respondents was different to that among non-respondents, no significant bias would be expected. ${ }^{10}$ Study characteristics which might have contributed to the high response rates include the use of experienced, salaried, well motivated, and trained, female interviewers; the cooperation of the Auckland schools; and our attempts to match the ethnic group of the study subject with that of the interviewer. However, it is also worth pointing out that the participation rates typical of North American epidemiologic studies $^{11}$ are low by New Zealand standards.

A potential weakness of this study is the problem of ascertaining the validity of parental reports of sensory deficit. Parents of injured children may have overstated the extent to which their children have deficits of hearing or vision. In addition, the fact that we did not collect information on whether the sensory deficits had been treated or corrected is also a potential source of exposure misclassification. For hearing, pure tone audiometry would have provided a more accurate measure. However, children injured as pedestrians often sustain severe head trauma, ${ }^{12}$ and since hearing loss is a common sequelae of head trauma, ${ }^{13}$ interpretation of audiometric findings would have been difficult.

Pless et al examined the contribution of sensory deficit in childhood traffic injuries using data from the British National Child Development Longitudinal Study. ${ }^{14}$ The outcome measure in this cohort analysis was all childhood traffic injuries requiring medical attention, although pedestrian injuries are likely to have comprised a large proportion of these injuries. In univariate analyses, boys aged 7-11 years with either impaired vision or hearing were at significantly increased risk of traffic injury (odds ratio $=1.5495 \% \mathrm{CI} 1.1$ to $2 \cdot 1)$. However, these results are likely to have underestimated the risk of pedestrian injury associated with sensory deficit. Since it is implausible that a sensory deficit would increase the risk of a motor vehicle occupant injury, the use of all traffic injuries as the outcome measure may have diluted a stronger association with pedestrian injuries.

In summary, these results suggest that children with sensory deficits constitute a high risk group for pedestrian injury. Because the prevalence of sensory deficit in the study population is low, the proportion of all pedestrian injury cases that is attributable to sensory deficit, the population attributable risk, is also low. In view of this, population measures such as more intensive screening of children for hearing loss would probably not be justified as a strategy for the prevention of pedestrian injuries. Nevertheless, it would seem appropriate that paediatricians caring for children with sensory disabilities take the increased risk of pedestrian injury into account and that they advise parents of the risk. The extent to which subclinical defects of hearing and vision increase the risk of pedestrian injury however remains open to speculation. Otitis media with effusion (OME) is often associated with mild hearing loss. Given prevalence estimates for OME of the order of $13 \%,{ }^{15}$ if the hearing loss which accompanies $\mathrm{OME}$ were associated with a modest increase in the risk of pedestrian injury, then this risk factor may be responsible for a significant proportion of cases.

This study was funded by the Health Research Council of New Zealand.

1 Kemp AM, Sibert JR. Epilespy and the risk of drowning. Arch Dis Child 1993; 68: 684-5.

2 Williams CE Accidents in mentally retarded children. Dev Med Child Neurol 1973; 15: 660-2.

3 Jackson RH. Hazards to children in traffic. Arch Dis Child 1978; 53: 807-13.

4 Sandels S. Children in traffic. London: Elek, 1975.

5 Rivara FP. Child pedestrian injuries in the United States. Am $\mathcal{F}$ Dis Child 1990; 144: 692-6.

6 Roberts I, Norton R, Jackson R, Dunn R, Hassall I. Effect of environmental factors on risk of child pedestrians by motor vehicles: a case-control study. $B M \mathcal{F} 1$ 1995; 310: 91-4.

7 Department of Statistics. Census of population and dwellings, March 1991. Welllington: Department of Statistics, 1991.

8 Elley WB, Irving JC. The Elley Irving socioeconomic index 1981 census revision. New Zeland fournal of Educational 1981 census revision. New
Studies 1985; 20: $115-28$.

9 Cornfield J. A statistical problem arising from retrospective studies. In: Neyman J, ed. Proceedings Third Berkeley studies. In: Neyman Symposium.

10 Rothman KJ. Modern epidemiology. Boston: Little, Brown and Company, 1986.

11 Maclure M. Asbestos and renal adenocarcinoma: a casecontrol study. Environ Res 1987; 42: 353-61.

12 Roberts I, Streat SJ, Judson JA, Norton RN. Critical injuries in paediatric pedestrians. NZ Med $\mathcal{F} 1991 ; 104$ 247-8.

13 Abd al Hady MR, Shehata O, el Mously M, Sallam FS Audiological findings following head trauma. $f$ Laryngo Otol 1990; 104: 927-36.

14 Pless IB, Peckham CS, Power C. Predicting traffic injuries in childhood: a cohort analysis. F Pediatr 1989; 115: 932-8.

15 Chalmers D, Stewart I, Silva P, Mulvena A. Otitis media with effusion in children: the Dunedin study. London: Mac Weith Press, 1989. 